\title{
Breast tuberculosis: a rare manifestation of extrapulmonary tuberculosis
}

\author{
MTMAshfaq ${ }^{1}$, Wasantha Kodikara Arachchi ${ }^{2}$ \\ ${ }^{I}$ Registrarin Medicine, ${ }^{2}$ Consultant Physician, Teaching Hospital, Karapitiya, Galle. \\ e-mail address of the corresponding author,Dr.M.T.M. Ashfaq: ashfaqthaha@yahoo.com
}

\section{Introduction}

Extrapulmonary tuberculosis occurring in the breast is extremely rare. Breast tuberculosis is uncommon even in countries where the incidence of pulmonary and extrapulmonary tuberculosis is high ${ }^{1-3}$. It is often mistaken for carcinoma or pyogenic breast abscess ${ }^{1,2}$. Diagnosis is based on the identification of typical histological features or the tubercle bacilli under microscopy or culture ${ }^{4}$. The disease is curable with antitubercular chemotherapeutic drugs.

\section{Case report}

A 36 year-old woman was admitted with complaints of intermittent fever, loss of appetite and a painful breast lump of two month duration. Other than the infrequent attacks of bronchial asthma her past medical history was unremarkable. On examination, she was febrile. Two hard, tender, mobile lumps were found in the upper outer quadrant of the right breast. No nipple retraction or discharge was seen. A solitary right axillary lymph node was found. All the other systems were clinically normal. On investigation, she had normal white blood cell count with lymphocyte predominance and high ESR. Repeated blood cultures were negative. Chest radiograph was normal. Ultrasound scan of the abdomen showed multiple hypoechoic lesions in the spleen. FNAC of the breast lump (Figure 1) and lymph node showed necrotizing caseating granulomatous lesions. Mantoux was strongly positive. Direct smear of splenic aspiration revealed acid fast bacilli and the culture (Figure 2) that followed was positive for Mycobacterium tuberculosis, thus confirming the diagnosis. Anti tubercular chemotherapy was commenced.

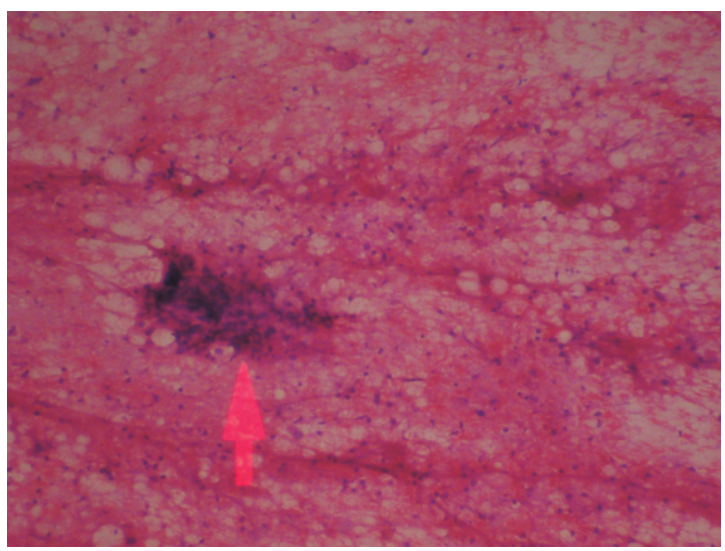

Figure 1 - FNAC of the breast lump

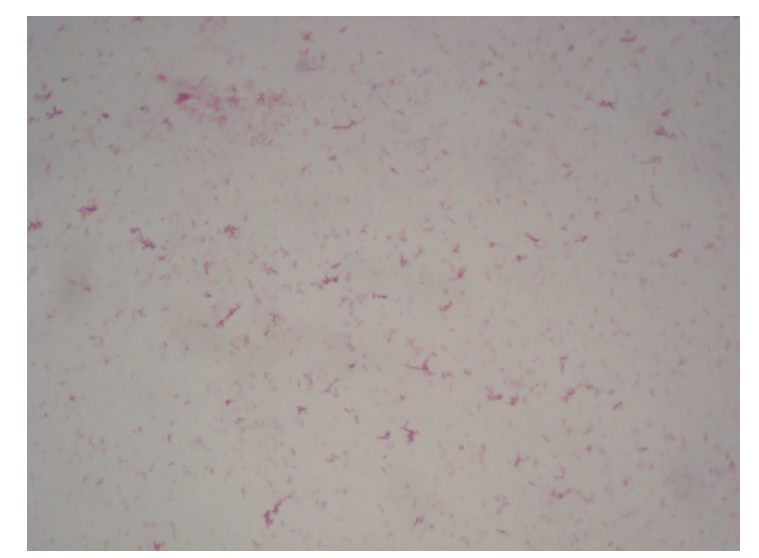

Figure 2 - Acid fast bacilli from the culture of the splenic aspirate

\section{Discussion}

Breast tissue is remarkably resistant to tuberculosis. Like skeletal muscles and spleen, it provides unfavourable environment for the survival and multiplication of tubercle bacilli ${ }^{5}$. Breast tuberculosis is classified as primary when the breast lesion is the only manifestation of tuberculosis, and secondary when there is a demonstrable focus of tuberculosis elsewhere in the body ${ }^{6}$. 
However, primary breast tuberculosis is probably quite rare and is diagnosed because the clinician is unable to detect the true focus of the disease. Breast tuberculosis is considered invariably secondary to a lesion elsewhere in the body ${ }^{7}$. Primary form may rarely result from infection of the breast through abrasions or through openings of the ducts in the nipple. The breast may become infected in a variety of ways (i) haematogenous, (ii) lymphatic, (iii) spread from contiguous structures, (iv) direct inoculation, and $(v)$ ductal infection ${ }^{6}$. The history of the presenting symptoms in breast tuberculosis is usually less than a year but varies from few months to several years ${ }^{5,8}$. Breast tuberculosis commonly affects women in their reproductive age group", between 21-30 years, similar to the highest incidence of pulmonary tuberculosis reported in the same age group of females ${ }^{10}$. In pregnant and lactating women, the breast is vascular with dilated ducts, predisposed to trauma making it more susceptible to tubercular infection $^{3,9}$. It is uncommon in prepubescent females and elderly women ${ }^{11}$. Breast tuberculosis is rare in males ${ }^{12}$. Bilateral involvement is uncommon ${ }^{3}$.

\section{Conclusion}

Although tuberculosis of breast is extremely rare, it should be kept in mind particularly in TB endemic countries.

\section{References}

1. Kalac N, Ozkan B, Bayiz H, Dursun AB, Demirag F. Breast tuberculosis. Breast 2002; 11:346-9.

2. Kakkar S, Kapila K, Singh MK, Verma K. Tuberculosis of the breast. A cytomorphologic study. Acta Cytol. 2000; 44: 292-6.
3. Banerjee SN, Ananthakrishnan N, Mehta RB, Prakash S. Tuberculous mastitis: a continuing problem. World J Surg. 1987; 11: 105-9.

4. Mallika Tewari \& H.S. Shukla. Department of Surgical Oncology, Institute of Medical Sciences, Banaras Hindu University, Varanasi, India. Indian J Med Res. August 2005; 122: 103-18.

5. Mukerjee P, George M, Maheshwari HB, Rao CP. Tuberculosis of the breast. J Indian Med Assoc. 1974; 62: $410-2$.

6. Mckeown KC, Wilkinson KW. Tuberculous diseases of the breast. Br J Surg. 1952; 39: 420.

7. Vassilakos P. Tuberculosis of the breast: cytological findings with fine-needle aspiration. A case clinically and radiologically mimicking carcinoma. Acta Cytol. 1973; 17: $160-5$.

8. Dubey MM, Agrawal S. Tuberculosis of the breast. J Indian Med Assoc. 1968; 51:358-9.

9. Shinde SR, Chandawarkar RY, Deshmukh SP. Tuberculosis of the breast masquerading as carcinoma: a study of 100 patients. World JSurg. 1995; 19: 379-81.

10. Shukla HS, Kumar S. Benign breast disorders in nonwestern populations: Part II - Benign breast disorders in India. World J Surg. 1989; 13: 746-9.

11. Hamit HF, Ragsdale T.H. Mammary tuberculosis. J R Soc Med. 1982; 75: 764-5.

12. Jaideep C, Kumar M, Khanna AK. Male breast tuberculosis. Postgrad MedJ. 1997; 73: 428-9. 